\title{
Replacement of Imported Long Fiber Kraft Pulp with Lignocellulosic Nanofibers and Cationic Materials in the Production of Durable Paper
}

\author{
Jafar Ebrahimpour Kasmani, ${ }^{\mathrm{a}, *}$ Hassan Mohammadpour, ${ }^{\mathrm{a}}$ and Ahmad Samariha ${ }^{\mathrm{b}}$ \\ Usage of cellulosic nanofibers, starch-nanocellulose, and polyacrylamide- \\ nanocellulose hybrid systems were investigated for the replacement of \\ imported long bleached kraft fibers in the production of durable papers. In \\ this study, imported softwood kraft pulp was added to cotton pulp at four \\ levels. Nanofibrillated cellulose (NFC) prepared from chemimechanical \\ pulp was added to cotton pulp at a $5 \%$ level with optional $1 \%$ cationic \\ starch or $0.1 \%$ cationic polyacrylamide. Comparative tests were done \\ without NFC at three levels of either cationic starch or cationic \\ polyacrylamide. For each condition, $80 \mathrm{gm}^{-2}$ handsheets were made, and \\ the physical, mechanical, and optical properties of the paper were \\ compared. The results showed that increases of NFC yielded higher \\ surface smoothness, tensile strength, resistance to bursting, tearing \\ energy, folding endurance, yellowness, and opacity. It also reduced \\ brightness and porosity whether added singly or in combination with \\ cationic starch or polyacrylamide. Increasing cationic starch also \\ increased surface smoothness, tensile strength, resistance to bursting, \\ and folding endurance, but paper opacity was reduced. The field emission- \\ scanning electron microscopy results showed that increased NFC reduced \\ porosity, the paper surface became smoother, and the pores were \\ relatively filled. Finally, the combined treatment of $5 \%$ NFC and $1 \%$ \\ cationic starch is introduced as a suitable combination.
}

Keywords: Long fiber chemical pulp; Nano lignocellulose; Cotton fiber; Physical properties; Optical properties

Contact information: a. Department of Wood and Paper Science Engineering, Savadkooh Branch, Islamic Azad University, Savadkooh, Iran; b. Department of Mechanical Engineering, Faculty of Enghelab-e

Eslami, Tehran Branch, Technical and Vocational University (TVU), Tehran, Iran;

*Corresponding author: Jafar_kasmani@yahoo.com

\section{INTRODUCTION}

Today, paper money is used as an integral part of society's business exchanges in everyday life and has been used everywhere and in all professions for a long time (Yazdani Aghmashhadi et al. 2016). Although the introduction of credit cards to the trading system in most countries, especially developed countries, has reduced the consumption level of paper money, the traditional paper currency continues to be favored in various markets with lower worth. The industry of manufacturing paper money is more complicated than printing and writing industries, because preservation from different criterion standards for this paper are important. Currently, according to the application of nanotechnology in different industrial areas, using nanoparticles in the papermaking industry has gained a special position, and its innovation and application have been developed gradually. Of the types of nanomaterials used in papermaking, nanofibrillated cellulose (NFC) is produced by high input of mechanical energy, which converts the fibers to into fibrillar structures, 
within which the fibrils are often branched and can have diameters in the range of about 5 to $100 \mathrm{~nm}$. Taking advantage of its specific size and characteristics, NFC has emerged as a strengthening aid along with cationic polymers, such as starch or cationic polyacrylamide. Recently, consuming NFC has drawn attention as a novel additive for improving paper strength properties (Rodriguez 2008; Asadpour et al. 2015; Moradian et al. 2016). Reports of recent studies have highlighted role of NFC in the improvement of paper strength (Hassan et al. 2011; González et al. 2012; Hii et al. 2012; Hadilam et al. 2013; Merayo et al. 2017; Balea et al. 2018). Effects of this material include the reduction of porosity, the enhancement of the inter-fiber joints, and the resistance against air passage (Hii et al. 2012; Charani et al. 2013; Sehaqui et al. 2013). The studies have indicated that using NFC can increase tensile strength and bonding between fibers, but sometimes it can reduce the tearing strength of paper and decrease the rate of drainage (Hadilam et al. 2013). Recently it's been found that combinations of nanofibrillated cellulose (NFC) with high ranges of cationic starch can achieve high increases in paper's tensile strength and stiffness in comparison to either additive on its own (Rice et al. 2018). Current studies confirmed that adding pre-combined cationic starch and NFC to papermaking furnish made it feasible to keep tensile strength and stiffness while reducing both the refining degree and the apparent density of the paper (Hubbe 2019). When the treated NFC was added to paper, a large increase in strength was observed. When the system was treated with colloidal silica (before adding the treated NFC to the papermaking fibers), a combination of high strength and good drainage was achieved (Rice et al. 2018).

In most of the studies concerning the application of nano-sized lignocellulosic material in papermaking, a cationic polymer has been used as an aid for maintenance (Charani et al. 2013; Petroudy et al. 2014). Nonetheless, if a cationic polymer has been added after the NFC particles, which have a negative charge, a more favorable effect in the durability of anionic nanoparticles and a reduction of drainage level can be expected because of the interactions of opposite charges. The first mechanism is that the starch increases interfiber bond strength, because its free hydroxyl groups on the anhydroglucose units can participate in hydrogen bonding. Water-soluble polymers that can form hydrogen bonds generally are able to serve as dry-strength additives. Starch and its derivatives are among common dry additives that are used in the papermaking industry. Starch with various mechanisms increases paper's dry-strength. In addition, dry strength additives can reduce the basis weight that is required to meet strength requirements of paper products; therefore, the speed of the paper machine may be increased. It is predicted that researchers can achieve more appropriate mechanical stregnth in paper by optimized usage of NFC material in the paper structure. Tajik et al. (2016) considered the effect of cationic polyacrylamide and NFC on mechanical, physical, and optical characteristics of bagasse bleached paper, and the results showed that the addition of cellulosic nanofiber and cationic polyacrylamide improve the drainage process and increase the durability of papers (Ahluwalia and Goyal 2007). Because cotton is pure in terms of alpha cellulose, has proper strength and long fiber, it can be the best option for producing different durable paper and specific papers such as tissue, print paper, album, paper money, and securities paper (Cerchi and Tullio 2006). The increase of the price of raw material in recent years has pushed this industry toward the substitution of some parts of consumed cotton with chemical pulp, in combination with dry-strength additives. Because paper strength characteristics are important to produce these papers, the overall price of this product will be reduced considerably if researchers gain proper results in the combination of cotton with treated chemical pulps. The inter-fiber bonds will be increased by using dry-strength 
additives (Hamzeh and Rostampur-Hafthkani 2008).

To produce paper money, desirable raw material should be used. The most crucial raw material for manufacturing this type of paper is cotton cellulosic fibers, because of their high purity (crystallite) compared with other natural fibers, have high strength and eternal durability. Therefore, more than $90 \%$ of durable papers have been made of cotton natural fibers. In global trading, because of the high price of cotton in comparison with other cellulosic fibers, the overall price of produced paper by cotton is more than other paper products that are made of other fibers. In addition, the required combination of strength properties for currency paper cannot be achieved by use of cotton alone. To compensate for the inadequate inter-fiber bonding, long fiber chemical pulp should be used in addition to the cotton fiber. Chemical pulp fibers, such as bleached kraft fibers, not only produce problems for companies economically, but also sometimes their preparation is not easy. Therefore, the present study aims to consider separate and combined additives of NFC along with cationic starch or cationic polyacrylamide for substituting them with long chemical paper pulp. Thus, the aim of this study is the addition and determination of the optimum level of nanofibrillated lignocellulose along with starch and cationic polyacrylamide additives to cotton paper pulp for feasibility of its substitution with long chemical paper pulp on a laboratory scale.

\section{EXPERIMENTAL}

\section{Materials}

Cotton pulp

Cotton pulp was obtained from Ehpak Ind. Co. (Mazandaran, Sari, Iran). It was refined using a PFI mill (LABTEC, Sari, Iran) to $250 \mathrm{~mL}$ Canadian Standard Freeness (CSF) prior to any treatment or handsheet making. Bleached softwood kraft pulp was bought from Irkutsk Oblast Co., Ust-ilimsk, Russia. It was refined in a PFI mill to $250 \mathrm{~mL}$ CSF prior to any treatment or handsheet making. The resulting pulp and paper were dewatered to a consistency of $10 \%$ to $15 \%$ and then put in plastic bags and kept in a refrigerator until consumption.

\section{Nano lignocellulose}

The nanofibrillated cellulose was prepared by Nano Novin Polymer Co. (Gorgan, Iran). Nano lignocellulose of this company was produced using bleached chemicalmechanical paper pulp produced from Mazandaran Wood and Paper Co. (Sari, Iran). Because the material contained lignin, it can also be referred to as nanofibrillated lignocellulose, which can be regarded as a subclass of NFC (also called CNF). With the super mill method, the average diameter of nanomaterials was less than $50 \mathrm{~nm}$.

\section{Cationic polyacrylamide}

The solution of cationic acrylamide copolymer was prepared by the method used by Charani et al. (2013). First, $0.01 \mathrm{~g}$ of polyacrylamide with a molecular weight of 359188 $\mathrm{g} / \mathrm{mol}$ was poured to a $100-\mathrm{mL}$ flask. Then, $1.5 \mathrm{~mL}$ of ethanol was added to it and after 2 min, $50 \mathrm{~mL}$ of distilled water was added to the flask and it was hand shaken for $2 \mathrm{~min}$. The contents of the flask were magnetically stirred for $3 \mathrm{~h}$. The flask containing polymer was kept in a refrigerator for $24 \mathrm{~h}$. Then, at the time of use, the contents of the flask were diluted to a volume of $100 \mathrm{~mL}$ by distilled water, and the whole mixture was stirred for $10 \mathrm{~min}$. 
The resulting polymer solution, with a concentration of $0.01 \%$, was used for increasing the retention and effectiveness of the NFC in the paper pulp suspension. Polyacrylamide was added at three levels of $0.05 \%, 0.1 \%$, and $0.15 \%$ based on the dry weight of pulp from polyacrylamide $1 \%$ solvent.

\section{Cationic starch}

Cationic starch was prepared from potato starch of Lyckeby Amylex Co. (Horažd'ovice, Czechia, Slovakia). The $\mathrm{pH}$ of cationic starch was approximately 6 and the degree of substitution was $0.035 \mathrm{~g} / \mathrm{mol}$, the protein level was $1.5 \%$, the nitrogen was $0.25 \%$, and the moisture was $10 \%$ based on fresh weight. To prepare the starch solution with the concentration of $0.5 \mathrm{~g} / \mathrm{cc}$ (i.e., $0.5 \mathrm{~g}$ pure starch in $100 \mathrm{cc}$ of water and starch solution), the amount of required impure starch was determined by considering the miniaturization percentage. A determined level of impure cationic starch was poured into an Erlenmeyer flask and its volume was reached to 100 by distilled water. During stirring, the temperature inside the Erlenmeyer flask was controlled by a thermometer and a foil sheet was put on the top of the Erlenmeyer flask as a lid to prevent evaporation. The Erlenmeyer flask was put on a heater for $30 \mathrm{~min}$ while its temperature gradually rose to 90 ${ }^{\circ} \mathrm{C}$, and it was then kept at this temperature for $30 \mathrm{~min}$. The resulting starch solution was prepared fresh daily and was consumed to prevent changes of viscosity and concentration from environmental effects. The cationic starch was added at three levels of $0.5 \%, 1 \%$, and $1.5 \%$ based on the dry weight of paper pulp. The cationic starch properties are presented in Table 1.

Table 1. Cationic Starch Properties

\begin{tabular}{|c|c|}
\hline Properties & Value \\
\hline Moisture & $14 \%$ \\
\hline Gelation Temperature & $70{ }^{\circ} \mathrm{C}$ \\
\hline Cooking Temperature & $90{ }^{\circ} \mathrm{C}$ \\
\hline $\mathrm{pH}$ & 6 \\
\hline Viscosity & 75.7 (cp) \\
\hline Degree of Substitution (DS) & 0.035 \\
\hline
\end{tabular}

\section{Methods}

Preparation of handsheets

After the primary preparation of chemical paper pulp and cotton pulp, the addition of NFC, polyacrylamide, and starch, 13 separated treatments were considered as below (Table 2):

1. Control treatments using cotton pulp and refined chemical pulp at four levels of $0 \%, 10 \%, 20 \%$, and $30 \%$ that were named with abbreviated codes of 0LP, 10LP, 20LP, and 30LP.

2. The treatments of $5 \%$ NFC, $5 \%$ cellulosic nanofiber and $1 \%$ starch, and $5 \%$ cellulosic nanofiber and $0.1 \%$ polyacrylamide were named with abbreviated codes of $5 \mathrm{NFC}, 5 \mathrm{NFC}+1 \mathrm{CS}$, and $5 \mathrm{NFC}+0.1 \mathrm{PAM}$.

3. Cotton fiber treatments along with three levels of cationic starch were indicated as $0.5 \mathrm{CS}, 1 \mathrm{CS}$, and 1.5CS. 
4. Treatments of cotton fibers and three levels of polyacrylamide were indicated as 0.05PAM, 0.1PAM, and 0.15 PAM.

According to Table 2, Ten handsheets of $80 \mathrm{~g} \cdot \mathrm{m}^{-2}$ were made based on standard regulations as per TAPPI T205 sp-02 (2002) and using a handsheet maker.

\section{Measurement of the paper properties}

The physical, mechanical, and optical characteristics of sheets, which are summarized in Table 3, were measured according to national and international standards.

Table 2. Combination of Under Studied Treatments and Consumption Levels of Cellulosic Nanofibers, Cationic Starch, and Polyacrylamide

\begin{tabular}{|c|c|c|c|c|c|c|}
\hline $\begin{array}{c}\text { Treatment } \\
\text { No. }\end{array}$ & Treatment Code & $\begin{array}{c}\text { Cotton } \\
\text { Pulp (\%) }\end{array}$ & $\begin{array}{c}\text { Long Fiber } \\
\text { Chemical } \\
\text { Pulp (\%) }\end{array}$ & $\begin{array}{c}\text { Nano-sized } \\
\text { Lignocell- } \\
\text { ulose (\%) }\end{array}$ & $\begin{array}{c}\text { Cationic } \\
\text { Starch } \\
(\%)\end{array}$ & $\begin{array}{c}\text { Polyacryl- } \\
\text { amide (\%) }\end{array}$ \\
\hline 1 & 0LP & 100 & 0 & 0 & 0 & 0 \\
\hline 2 & $10 \mathrm{LP}$ & 90 & 10 & 0 & 0 & 0 \\
\hline 3 & $20 \mathrm{LP}$ & 80 & 20 & 0 & 0 & 0 \\
\hline 4 & $30 \mathrm{LP}$ & 70 & 30 & 0 & 0 & 0 \\
\hline 5 & 5 NLC & 95 & 0 & 5 & 0 & 0 \\
\hline 6 & 5 NLC + 1CS & 94 & 0 & 5 & 1 & 0 \\
\hline 7 & 5 NLC + 0.1PAM & 94.9 & 0 & 5 & 0 & 0.1 \\
\hline 8 & $0.5 \mathrm{CS}$ & 99.5 & 0 & 0 & 0.5 & 0 \\
\hline 9 & $1 \mathrm{CS}$ & 99 & 0 & 0 & 1 & 0 \\
\hline 10 & $1.5 \mathrm{CS}$ & 98.5 & 0 & 0 & 1.5 & 0 \\
\hline 11 & $0.05 \mathrm{PAM}$ & 99.95 & 0 & 0 & 0 & 0.05 \\
\hline 12 & $0.1 \mathrm{PAM}$ & 99.9 & 0 & 0 & 0 & 0.1 \\
\hline 13 & $0.15 \mathrm{PAM}$ & 99.85 & 0 & 0 & 0 & 0.15 \\
\hline
\end{tabular}

Table 3. Tested Physical and Mechanical Characteristics

\begin{tabular}{|c|c|c|}
\hline No. & Properties Tested & Standard Number \\
\hline 1 & Porosity & TAPPI T460 om-02 (2002) \\
\hline 2 & Surface smoothness & TAPPI T555 om-04 (2004) \\
\hline 3 & Tensile strength index & TAPPI T494 om-01 (2001) \\
\hline 4 & Folding strength & TAPPI T423 cm-98 (1998) \\
\hline 5 & Burst resistance index & TAPPI T403 om-02 (2002) \\
\hline 6 & Tear resistance index & TAPPI T414 om-04 (2004) \\
\hline 7 & Brightness, opacity, and yellowness & TAPPI T452 om-98 (1998) \\
\hline
\end{tabular}

Scanning electron microscopy (SEM)

In this study, an electron microscope type MIRA3 TESCAN (TESCAN, Libušina, Czech Republic), set at a $0.5 \mathrm{kV}$ to $30 \mathrm{kV}$ accelerating voltage, was used.

\section{Statistical analysis}

The statistical plot of the present study was completely random; to perform data analysis, a one-way variance analysis was performed and mean grouping was done using the Duncan test at $95 \%$ assurance level via SPSS software (IBM Software, v.23, Armonk, NY, USA). 


\section{RESULTS AND DISCUSSION}

The F-value and significant level results are shown in Table 4.

\section{Surface smoothness and porosity}

The porosity indirectly shows the inner structure of paper and is related to strength characteristics, appearance, and the requirements of the paper's final consumption. As is shown in Fig. 1b, the lowest porosity level was due to the application of 5\% nanocellulose and $1 \%$ cationic starch, which yielded an air permeablity of $500 \mathrm{~mL} / \mathrm{min}$. The highest permeability level was reached with the use of $30 \%$ imported chemical fibers, giving a value of $1650 \mathrm{~mL} / \mathrm{min}$. The lowest level of porosity was observed for the use of NFC singly and in combination with cationic starch. This phenomenon is the result of the effective absorption of cationic starch on surfaces in the fiber network. The efficient adsorption can be attributed to the positive charge of cationic starch and its attraction to the negatively charged surfaces of the fibers.

According to previous studies, porosity is reduced at increased levels of cellulosic fines. The reason for this is that pores are filled with fines and fillers, so air flow cannot pass through them (Nazeri 2007). Moreover, better dispersion of NFC reduces the porosity (Hubbe and Gill 2004). The Duncan test divided the various means of porosity into five different groups. It is observable in Fig. 1a the highest level of surface smoothness was due to consumption of $1.5 \%$ cationic starch, giving a value of $2033 \mathrm{~mL} / \mathrm{min}$ and the lowest level was related to the application of $30 \%$ imported long fiber, giving $1533 \mathrm{~mL} / \mathrm{min}$.

Table 4. Variance Analysis (F-Value and Significant Level)

\begin{tabular}{|c|c|}
\hline Characteristics & Variables \\
\hline Surface Smoothness $\left(\mathrm{mL} . \mathrm{min}^{-1}\right)$ & $24.26^{*}$ \\
\hline Porosity $\left(\mathrm{mL} . \mathrm{min}^{-1}\right)$ & $19.66^{\star}$ \\
\hline Tensile Strength Index & $4.73^{\star}$ \\
\hline Tear Resistance Index & $7.54^{*}$ \\
\hline Burst Resistance Index & $35.37^{*}$ \\
\hline Folding Strength & $336.37^{*}$ \\
\hline Opacity & $5.08^{*}$ \\
\hline Brightness & $5.29^{\star}$ \\
\hline Yellowness & $340865.81^{*}$ \\
\hline${ }^{*}$ Significance level $=95 \%, \mathrm{~ns}=$ non significant \\
\hline \multicolumn{2}{|c|}{}
\end{tabular}

Surface smoothness is one of the most crucial structural characteristics, and it has gained more importance in specific functions especially for better printability and print quality (Elyasi et al. 2016). This characteristic is mainly affected by the average length of the fibers and the presence of fines and their stability in the paper network and their formation quality; therefore, in a determined combination, it determines the function of additives in paper pulp suspension (Hamzeh and Rostampur-Hafthkani 2008). The addition of NFC and the enhancement of starch and cationic polyacrylamide relatively increase surface smoothness; these materials, because of their natures, act to strengthen the paper. The mechanism may involve complexation among oppositely charged substance, giving a gelling effect. The integration of fine cellulosic material within the porous structure of the fiber network contributes to surface smoothness. 

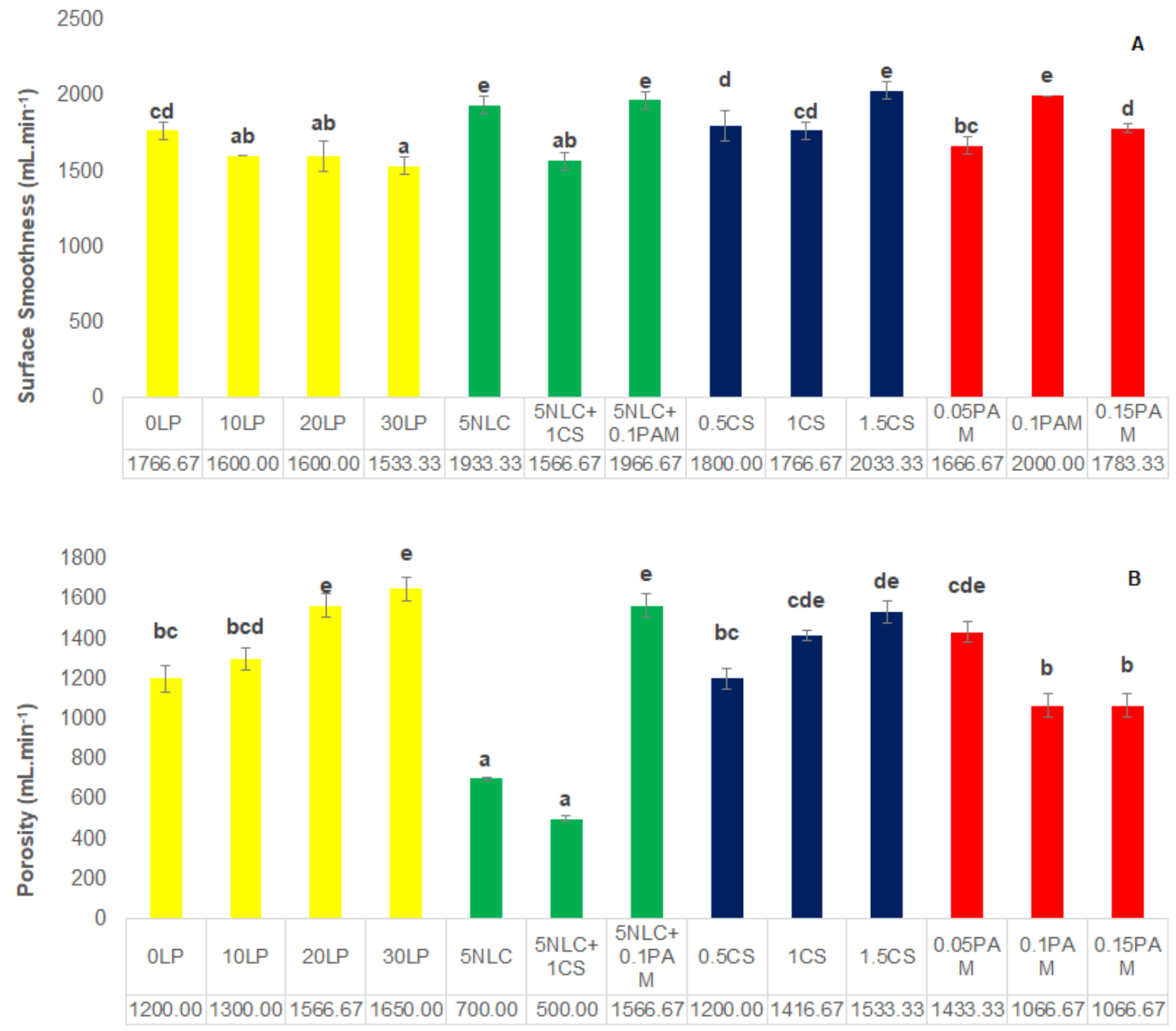

Fig. 1. Mean comparisons of averages grouping: A) surface smoothness, and B) porosity

\section{Tensile strength index of handsheets}

Figure 2 indicates the mean tensile strength index for 13 types of paper pulp. Duncan's grouping categorized the mean of tensile strength index into four different classes. The highest tensile strength was obtained by applying $1 \%$ cationic starch, yielding a value of $2.76 \mathrm{Nm} / \mathrm{g}$ and was grouped at class D. Tensile strength can be regarded as a good index for interfiber bonding, which is important for various strength properties (Kasmani et al. 2013).

Tensile strength is affected by the two key factors of intrinsic strength of fibers and strength of interfiber bonding. Because addition of NFC and starch cannot change the inherent strength of fibers, during the use of NFC and especially cationic starch, the tensile strength of paper was increased. In fact, with more NFC and cationic starch, the connectivity between fibers was increased, leading to increased tensile strength of the paper. Moreover, as the size of particles gets smaller up to nm scale, the specific surface of cellulosic fibers is increased. This means that more hydroxyl groups are available that can form hydrogen bonds with adjacent nanofibers, and eventually they form a network of nanofibers and increase this strength (Yousefi et al. 2011). 


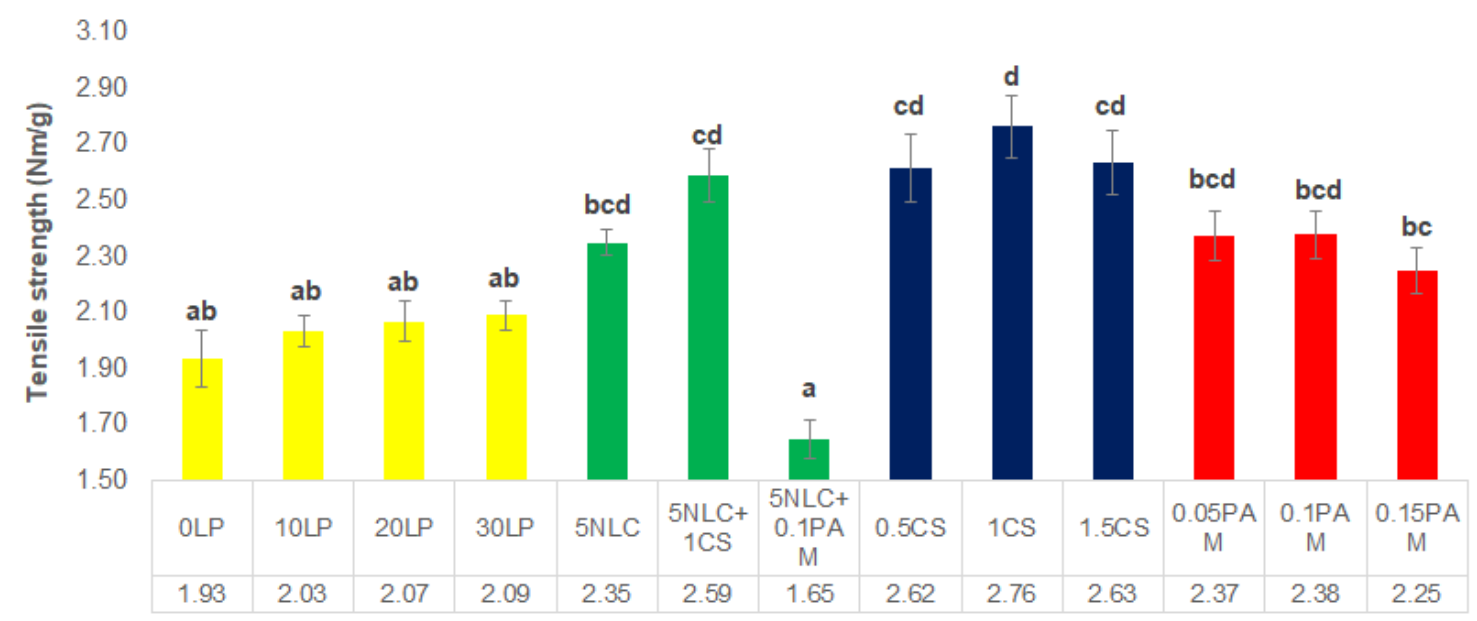

Fig. 2. Mean comparisons of paper tensile strength and grouping the means Bursting strength index of handsheets

Figure 3 shows the mean bursting strength index for 13 types of paper pulp. The Duncan's grouping put the mean of bursting strength index into 8 different classes. The highest bursting strength was obtained by applying $1.5 \%$ of cationic starch. Bursting strength is among those strengths that is related to fiber length and the amount of connection between fibers, but mostly it is affected by the joints between the fibers (Asadpour et al. 2008; Akbarpour and Resalati 2011). The highest bursting strength was obtained by applying cationic starch and lignocellulosic nanofiber in combination with starch. The enhancement of bursting strength occurs when free hydroxyl groups of starch are involved in the formation of greater numbers of hydrogen bonds. Moreover, there is an ionic bonding interaction between the positive charge of starch and the negative charge of the fibers; therefore, the connection power between the fibers increased. The highest bursting strength was obtained by applying cationic starch in combination with 5\% nanocellulose.

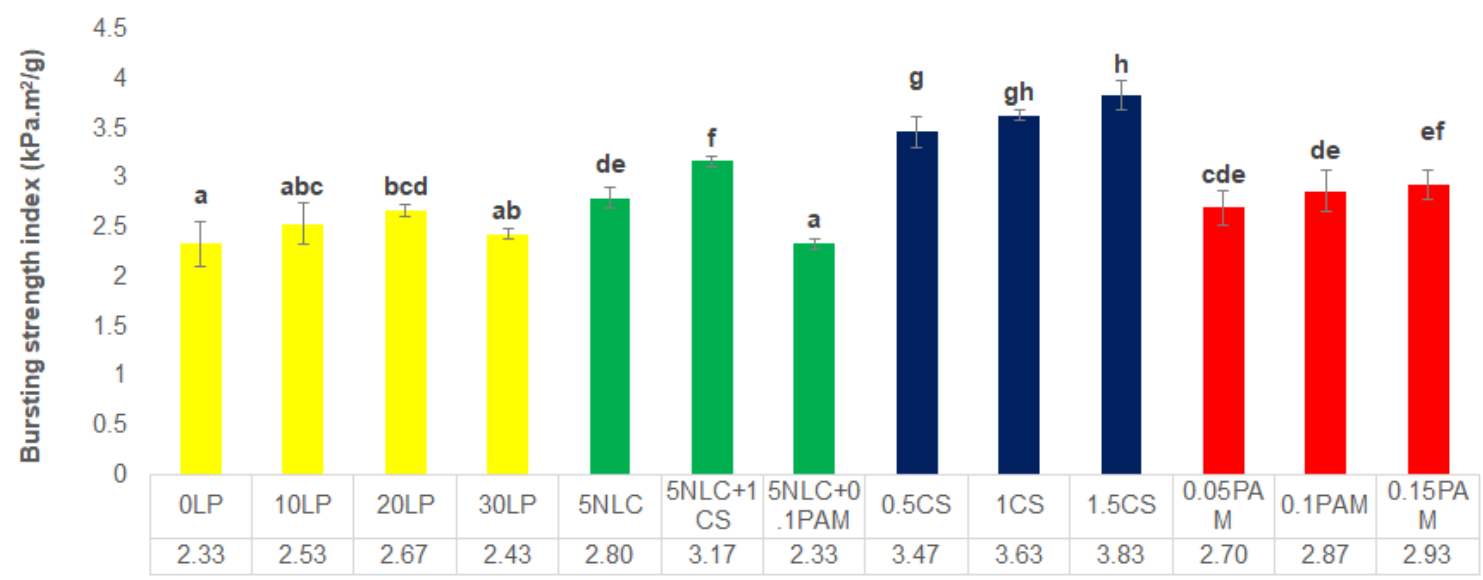

Fig. 3. Mean comparisons of paper bursting strength and grouping the means

\section{Tearing strength index of handsheets}

The main factors affecting tearing strength included the mean of fibers' length and diameter, inherent strength of fibers, the number of joints between the fibers, and the strength of fibers in papermaking, although the number of components linking and their 
orientation in paper structure are effective as well. Figure 4 shows the mean of the tearing strength index for 13 types of paper pulp. The Duncan's grouping put the mean of the tearing strength index into 7 different classes. The highest tearing strength was obtained at group $\mathrm{G}$ by applying $0.05 \%$ of polyacrylamide. Moreover, the level of tearing strength increased via the application of $1 \%$ starch and in combination of NFC and cationic starch. The reason of such enhancement is fiber flexibility, increasing the number and strength of interfiber connections. In addition, $0 \%$ imported nanofiber produced the lowest tearing strength. The addition of NFC reduced the tearing strength relatively. A similar procedure has been reported on the reduction of the tearing strength of combined papers and NFCcontaining papers. In the reports, the reasons of changes were introduced as inherent strength of fibers and the level of hydrogen bonds (Fathi and Kasmani 2019).

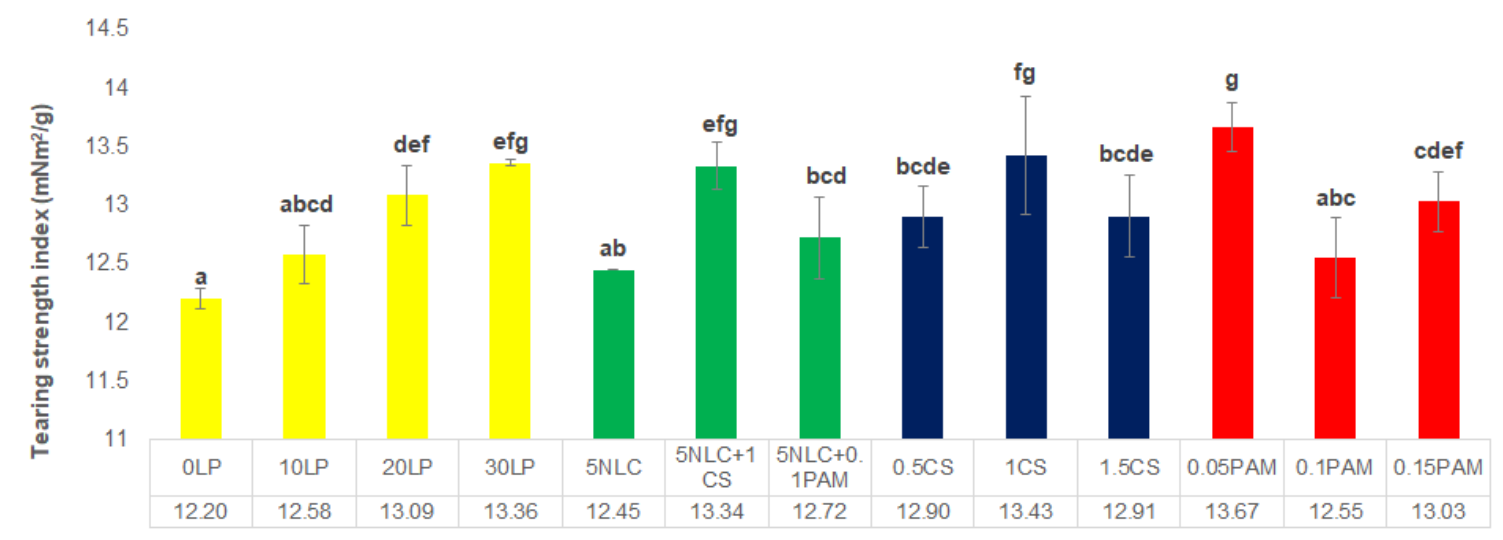

Fig. 4. Mean comparisons of paper tearing strength and grouping the means

\section{Folding strength index of handsheets}

The folding strength of handsheets is a crucial index for durable papers, especially paper money. This strength is affected by fiber flexibility. If the fibers are short and fragile and the joints are weak, the folding strength will be reduced. Figure 5 shows the mean of folding strength for 13 types of pulp. The Duncan test classified the folding strength into 7 different groups.

The least strength was observed in the case of to $0 \%$ long-fibered pulp with the mean of 25 pairs fold, which was classified in group A. The highest strength was related to $5 \%$ nanocellulose and $1 \%$ cationic starch with 1419 double-folds, which was classified in group $\mathrm{G}$.

The results showed that the effect of $1 \%$ cationic starch in combination with nanocellulose and $1.5 \%$ cationic starch was more extreme and can be explained as the enhancement of fiber specific surface and fiber network strength by the help of hydrogen bonds. The enhancement of folding strength as a result of the presence of cationic starch happens because the presence of cationic agents results in a more homogenous distribution of nanocellulosic fibers in the paper network and homogenous. 


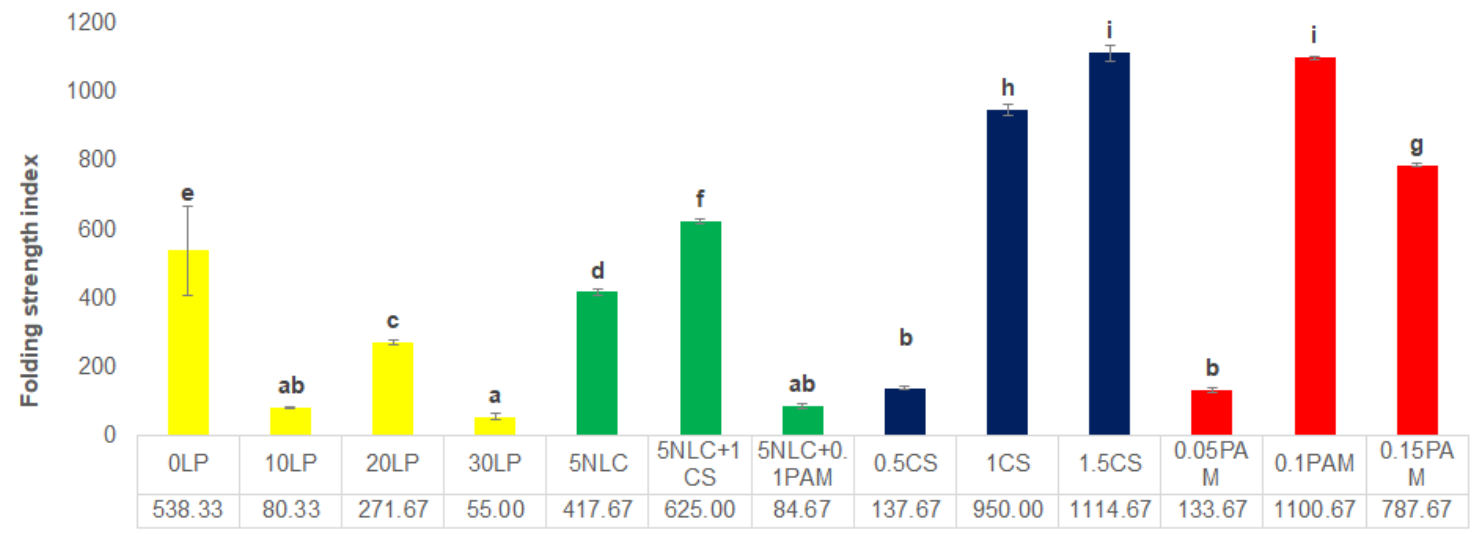

Fig. 5. Mean comparisons of paper folding strength and grouping the means

Optical characteristics of handsheets

Brightness and opacity are affected by pulp optical characteristics and dispersion manner of fillers in the paper. Opacity is crucial for durable papers such as paper money.
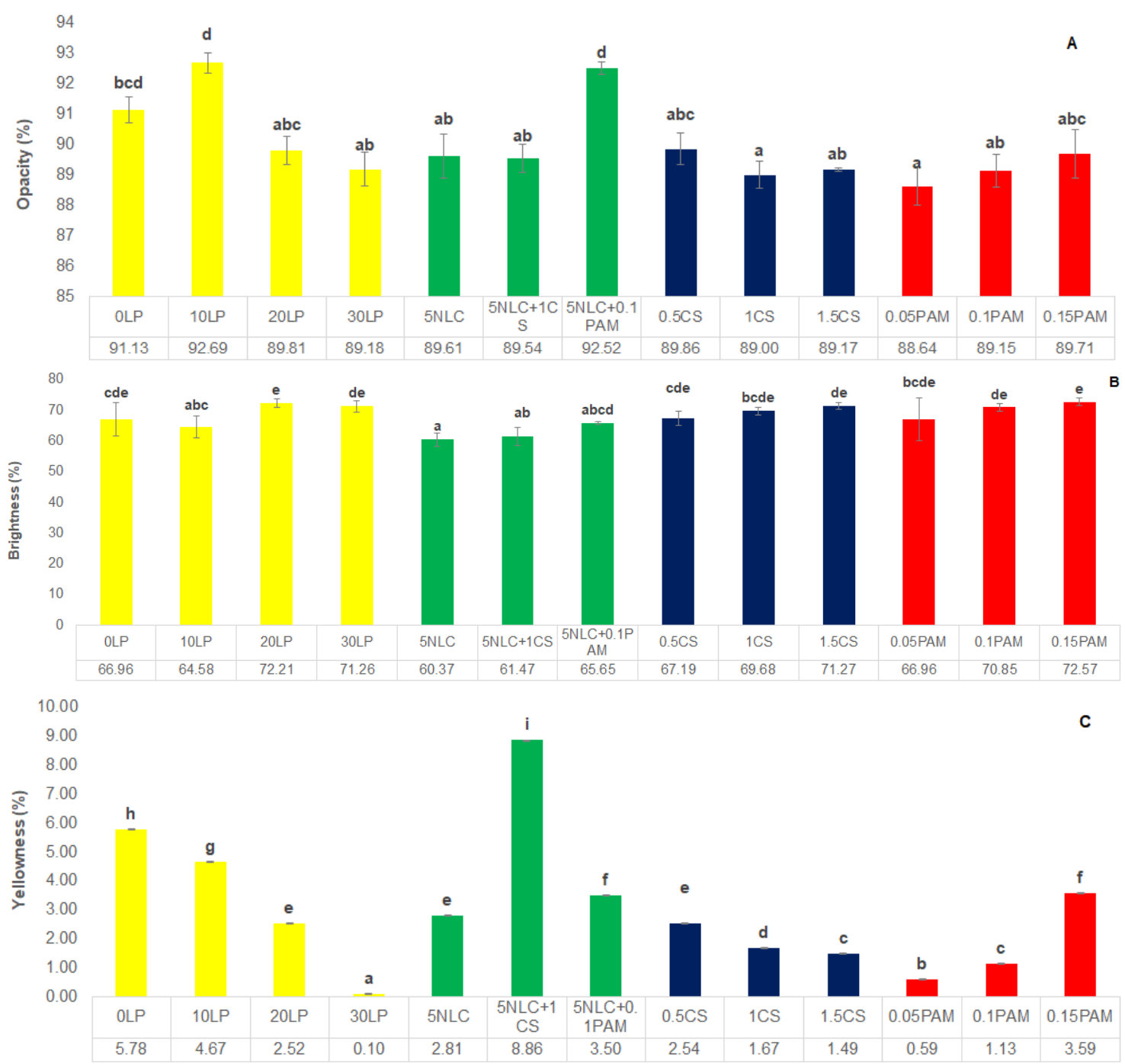

Fig. 6. The mean comparison of mean grouping: A) opacity, B) brightness, and C) yellowness 
Figure 6a shows the mean of opacity resistance changes for 13 types of paper pulp. Duncan's grouping put the mean of opacity index into 4 different classes. The lowest opacity was obtained at group A by applying $0.05 \%$ polyacrylamide, which yielded a values of $88.6 \%$. The enhancement of cationic starch reduced opacity. Research shows that during the usage of NFC separately and in combination with cationic polyacrylamide, the opacity was reduced. This reduction can be attributed to the increased bonding and higher density, which will reduce porosity the and specific surface area within the sheet (Brodin et al. 2014). Figure $6 \mathrm{~b}$ shows the mean of brightness resistance changes for 13 types of paper pulp. Duncan's grouping put the mean of brightness data into 5 different classes. The lowest brightness was obtained at group A by applying 5\% NFC.

Figure $6 \mathrm{c}$ shows the mean of yellowness resistance changes for 13 types of paper pulp. The Duncan grouping put the mean of yellowness data into 9 different classes. The lowest yellowness was obtained at group A by applying $20 \%$ imported long fibers.

\section{Microscopic studies of paper structure (field emission-scanning electron microscopy}

Figures 7 and 8 show FE-SEM images for $100 \%$ cotton pulp ( $0 \%$ chemical pulp), NFC, and a combination of NFC-starch and NFC-polyacrylamide.
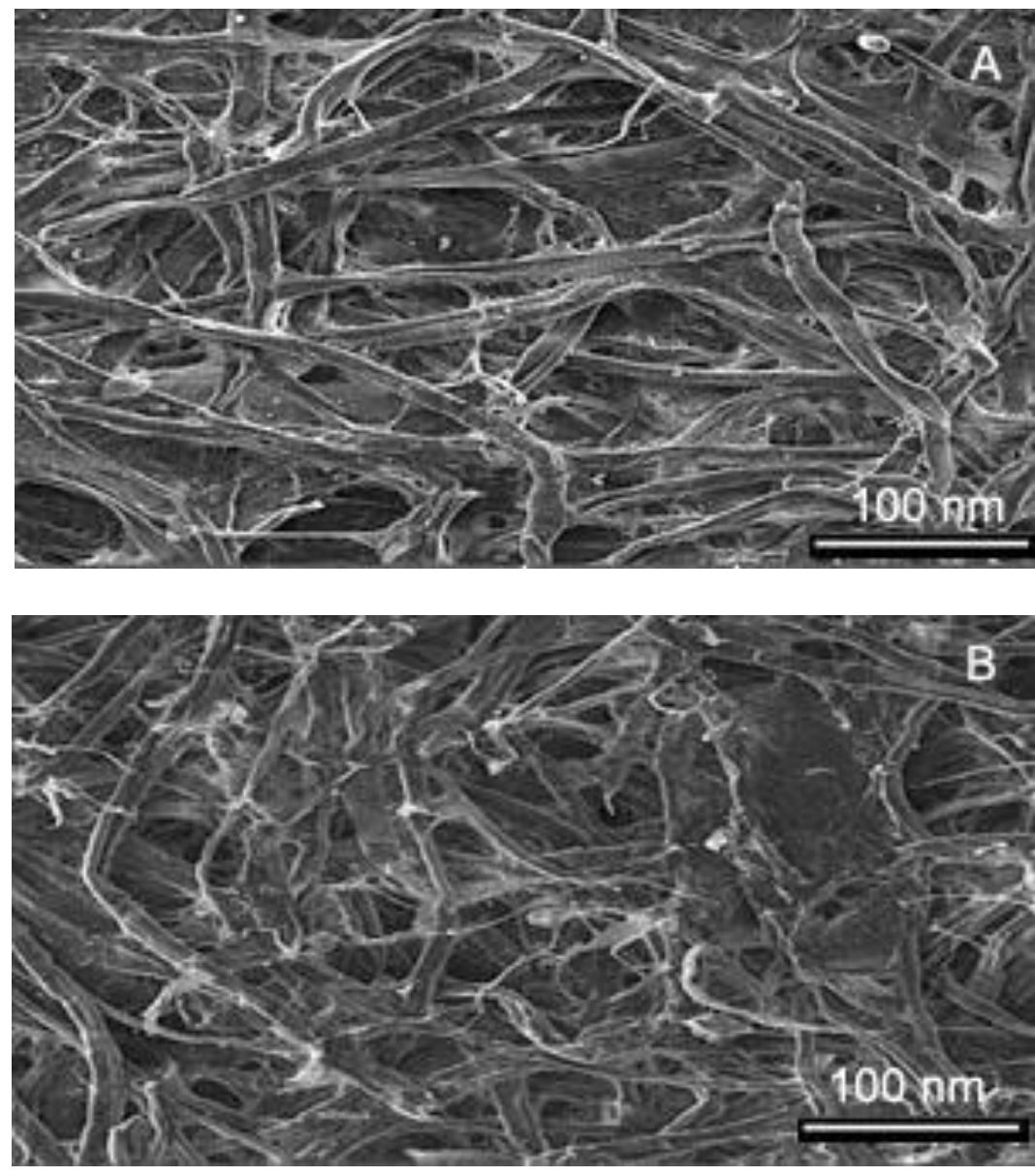

Fig. 7. The surface of paper pulp of A) $0 \%$ chemical pulp, and B) $30 \%$ chemical pulp 

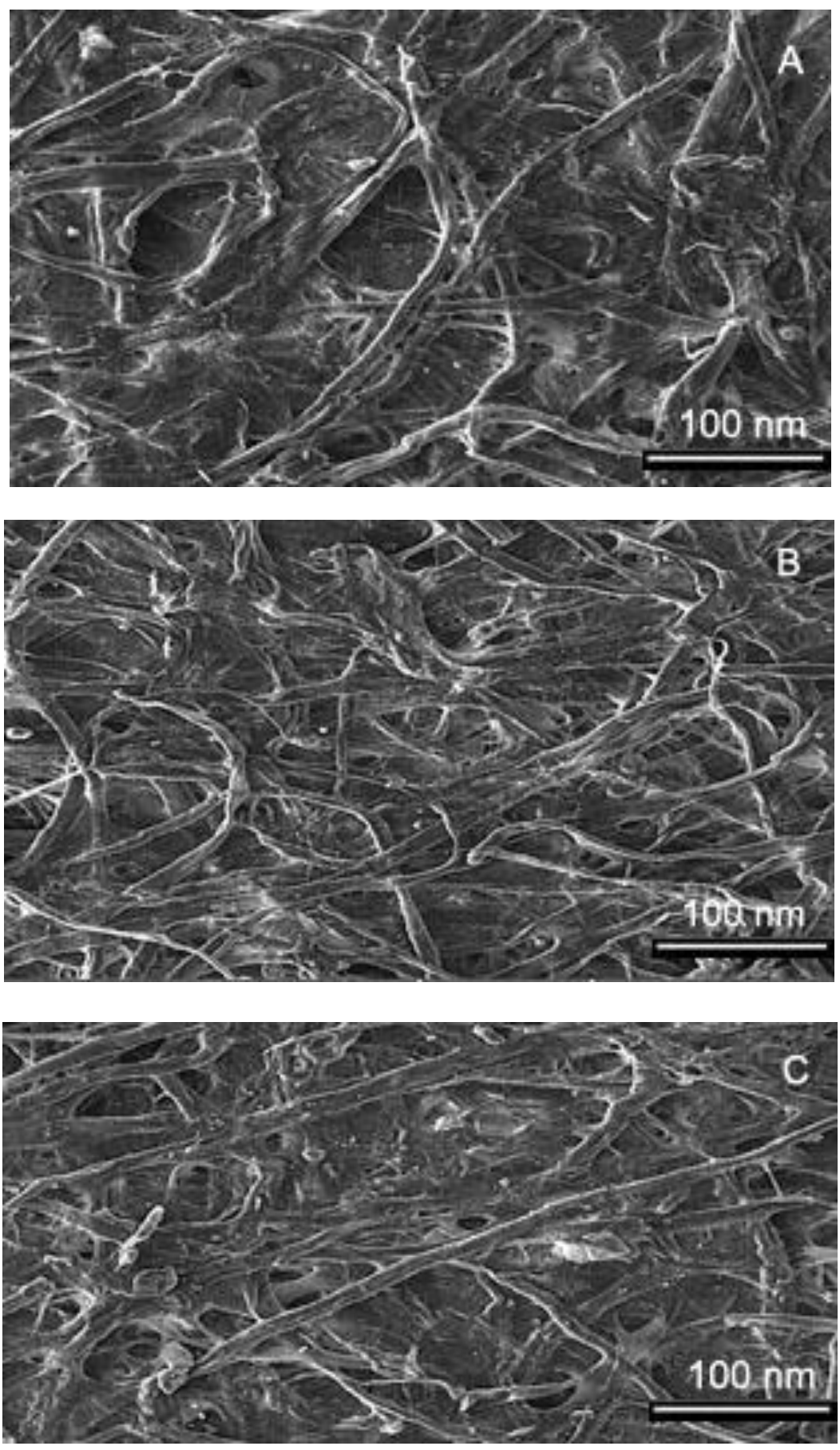

Fig. 8. The surface of paper pulp of A) $5 \%$ nano lignocellulosic fibers and $1 \%$ starch, B) $5 \%$ nano lignocellulosic fibers and $0.10 \%$ polyacrylamide, and C) $5 \%$ nano lignocellulosic fibers

There were pores and micrometer ruggedness in the paper that was prepared from cotton fibers, while in the paper that was prepared from NFC and polyacrylamide, pores and roughness were at the nanometer scale. Under the effect of the addition of 5\% NFC, the surface of paper becomes smoother and the gaps are relatively filled, and the results of surface smoothness and porosity confirm this issue. By adding NFC, the pores of the paper were filled and the results in Fig. 1b show that the porosity was at its lowest when using these nanomaterials. 


\section{CONCLUSIONS}

The purpose of the present study was to evaluate the effects of adding an optimum level of nanofibrillated cellulose (NFC) obtained from chemimechanical pulp along with either cationic starch or cationic polyacrylamide to cotton pulp. Feasibility studies were carried out for the substitution of imported bleached softwood kraft fibers at the laboratory scale. Usually the addition of chemical long fiber, NFC, cationic starch, and polyacrylamide to cotton pulp can relatively improve characteristics of resulted paper; but each of them has limitations in the production system.

1. Regarding the overall results, it was determined that with the increment of the softwood kraft fiber pulp, the porosity, tensile strength, tearing strength, and brightness were increased, while smoothness, folding strength, yellowness, and opacity were reduced.

2. The results indicated that by increasing the content of NFC, whether separately or in combination with cationic starch or cationic polyacrylamide, it was possible to increase the surface smoothness, tensile strength, bursting strength, tearing resistance, folding resistance, yellowness, and opacity, while brightness and porosity were decreased.

3. The increasing of cationic polyacrylamide reduced tensile strength, bursting strength, and folding strength, while it decreased porosity and opacity.

4. The increasing of cationic starch increased surface smoothness, tensile strength, bursting strength, and folding resistance, while it reduced opacity.

5. Imaging by FE-SEM showed that the addition of NFC reduced the size of pores at the paper surface, so that under the effect of the addition of NFC the surface became smoother and pores were filled, and the results of surface smoothness and porosity confirmed such issue.

6. The combined treatment of 5\% NFC and $1 \%$ cationic starch is introduced as a suitable combination.

\section{REFERENCES CITED}

Ahluwalia, S. S., and Goyal, D. (2007). "Microbial and plant derived biomass for removal of heavy metals from wastewater," Bioresource Technology 98(12), 22432257. DOI: 10.1016/j.biortech.2005.12.006

Akbarpour, A., and Resalati, H. (2011). "The effect of different concentrations of cellulase enzyme on optical and physical properties of ONP deinked pulp," Iranian Journal of Wood and Paper Industries 2(1), 1-15.

Asadpour, G., Ghasemian, A., Saraeian, A., and Ghaffari, M. (2008). "Quality of recycled OCC pulps and allows optimal use in combination with hardwood NSSC pulp wood pulp in Mazandaran," in: Proceedings of First Iranian Conference on Supplying Raw Materials and Development of Wood and Paper Industries, Gorgan, Iran, pp. 25-32. 
Asadpour, G., Resalati, H., Dehghani, M. R., Ghasemian, A., and Mohammad Nazhad, M. (2015). "Comparison of using single and dual retention aid system on newspaper pulp properties," Wood and Forest Science and Technology 22(2), 75-93.

Balea, A., Merayo, N., Fuente, E., Negro, C., Delgado-Aguilar, M., Mutje, P., and Blanco, A. (2018). "Cellulose nanofibers from residues to improve linting and mechanical properties of recycled paper," Cellulose 25(2), 1339-1351.

Brodin, F. W., Gregersen, Ø. W., and Syverud, K. (2014). "Cellulose nanofibrils: Challenges and possibilities as a paper additive or coating material-A review," Nordic Pulp \& Paper Research Journal 29(1), 156-166. DOI: 10.3183/NPPRJ-2014-29-01-p156-166

Cerchi, G., and Tullio, M. (2006). "Cellulose tissue paper including cotton fibers," European Patent No. 1676956.

Charani, P. R., Dehghani-Firouzabadi, M., Afra, E., Blademo, Å., Naderi, A., and Lindström, T. (2013). "Production of microfibrillated cellulose from unbleached kraft pulp of kenaf and Scotch pine and its effect on the properties of hardwood kraft: Microfibrillated cellulose paper," Cellulose 20(5), 2559-2567. DOI: 10.1007/s10570013-9998-Z

Elyasi, S., Jalali-Torshizi, H., and Resalati, H. (2016). "Investigation on the effect of different levels of alum consumption in alun-rosin sizing on the properties of plyboard," Journal of Forest and Wood Products 69(2), 375-385.

Fathi, G., and Kasmani, J. E. (2019). "Prospects for the preparation of paper money from cotton fibers and bleached softwood kraft pulp fibers with nanofibrillated cellulose,” BioResources 14(2), 2798-2811. DOI: 10.15376/biores.14.2.2798-2811

González, I., Boufi, S., Pèlach, M. A., Alcalà, M., Vilaseca, F., and Mutjé, P. (2012). "Nanofibrillated cellulose as paper additive in eucalyptus pulps," BioResources 7(4), 5167-5180. DOI: 10.15376/biores.7.4.5167-5180

Hadilam, M. M., Afra, E., and Yousefi, H. (2013). "Effect of cellulose nanofibers on the properties of bagasse paper," Forest and Wood Product 66(3), 351-366.

Hamzeh, Y., and Rostampour-Haftkhani, A. (2008). Principles of Papermaking Chemistry, University of Tehran Press, Tehran, Iran.

Hassan, E. A., Hassan, M. L., and Oksman, K. (2011). "Improving bagasse pulp paper sheet properties with microfibrillated cellulose isolated from xylanase-treated bagasse," Wood and Fiber Science 43(1), 76-82.

Hii, C., Oyvind, W. G., Chinga-Carrasco, G., and Eriksen, O. (2012). "The effect of MFC on the press ability and paper properties of TMP and GCC based sheets," Nordic Pulp \& Paper Research Journal 27(2), 388-396. DOI: 10.3183/npprj-2012-27-02-p388396

Hubbe, M. A., and Gill, R. A. (2004). "Filler particle shape vs. paper properties - A review," in: Proceedings of Spring Technology Conference, TAPPI Press, Atlanta, GA, USA, pp. 1-5.

Hubbe, M. A. (2019). "Nanocellulose, cationic starch and paper strength," APPITA Journal 72(2), 82.

Kasmani, J. E., Mahdavi, S., Alizadeh, A., Nemati, M., and Samariha, A. (2013). "Physical properties and printability characteristics of mechanical printing paper with LWC," BioResources 8(3), 3646-3656. DOI: 10.15376/biores.8.3.3646-3656

Merayo, N., Balea, A., de la Fuente, E., Blanco, Á., and Negro, C. (2017). "Synergies between cellulose nanofibers and retention additives to improve recycled paper properties and the drainage process," Cellulose 24(7), 2987-3000. 
Moradian, M. H., Charani, P., and Saadatnia, M. (2016). "Improving paper breaking length using cellulosic nanofibers in bagasse pulp," Forest and Wood Product 69(3), 603-614. DOI: 10.22059/JFWP.2016.59898

Nazeri, A. (2007). "Study the effects of fines particles on properties of physical and optical newsprint made from chemical-mechanical pulp," Iranian Journal of Wood and Paper Science Research 22(1), 29-40.

Petroudy, S. R. D., Syverud, K., Chinga-Carrasco, G. Ghasemain, A., and Resalati, H. (2014). "Effects of bagasse microfibrillated cellulose and cationic polyacrylamide on key properties of bagasse paper," Carbohydrate Polymers 99, 311-318. DOI: 10.1016/j.carbpol.2013.07.073

Rice, M. C., Pal, L., Gonzalez, R., and Hubbe, M. A. (2018). "Wet-end addition of nanofibrillated cellulose pretreated with cationic starch to achieve paper strength with less refining and higher bulk," TAPPI J, 17(7), 395-403.

Rodriguez, J. M. (2008). Micro and Nanoparticles in Papermaking, Translated to Persian by A. J. Latibari, A. Khosravani, and S. M. H. Nabavi (2011). Ayzh Publication, Tehran, Iran.

Sehaqui, H., Berglund, L. A., and Zhou, Q. (2013). "Biorefinery: Nanofibrillated cellulose for enhancement of strength in high-density paper structures," Nordic Pulp \& Paper Research Journal 28(2), 182-189. DOI: 10.3183/npprj-2013-28-02-p182189

Tajik, M., Resalati, H., Hamzeh, Y., Torshizi, H. J., Kermanian, H., and Kord, B. (2016). "Improving the properties of soda bagasse pulp by using cellulose nanofibers in the presence of cationic polyacrylamide," BioResources 11(4), 9126-9141. DOI: 10.15376/biores.11.4.9126-9141

TAPPI T205 sp-02 (2002). "Forming handsheets for physical tests of pulp," TAPPI Press, Atlanta, GA, USA.

TAPPI T248 sp-00 (2000). "Laboratory beating of pulp (PFI mill method)," TAPPI Press, Atlanta, GA, USA.

TAPPI T403 om-02 (2002). "Bursting strength of paper," TAPPI Press, Atlanta, GA, USA.

TAPPI T414 om-04 (2004). "Internal tearing resistance of paper (Elmendorf-type method)," TAPPI Press, Atlanta, GA, USA.

TAPPI T423 cm-98 (1998). "Folding endurance of paper" TAPPI Press, Atlanta, GA, USA.

TAPPI T452 om-98 (1998). "Brightness of pulp, paper and paperboard (directional reflectance at $457 \mathrm{~nm})$," TAPPI Press, Atlanta, GA, USA.

TAPPI T460 om-02 (2002). "Air resistance of paper (Gurley method)," TAPPI Press, Atlanta, GA, USA.

TAPPI T494 om-01 (2001). "Tensile properties of paper and paperboard (using constant rate of elongation apparatus)," TAPPI Press, Atlanta, GA, USA.

TAPPI T555 om-04 (2004). "Roughness of paper and paperboard (print-surf method)," TAPPI Press, Atlanta, GA, USA.

Yazdani Aghmashhadi, O., Asadpour Atoee, G., Rasooly Garmaroody, E., and Iman, R. (2016). "Application of nano silver in the production of antibacterial bank-note," Iranian Journal of Wood and Paper Science Research 31(1), 166-179. 
Yousefi, H., Nishino, T., Faezipour, M., Ebrahimi, G., and Shakeri, A. (2011). "Direct fabrication of all-cellulose nanocomposite from cellulose microfibers using ionic liquid-based nanowelding," Biomacromolecules 12(11), 4080-4085. DOI: $10.1021 / \mathrm{bm} 201147 \mathrm{a}$

Article submitted: September 25, 2020; Peer review completed: January 9, 2021; Revised version received: March 22, 2021; Accepted: March 29, 2021; Published: April 1, 2021. DOI: 10.15376/biores.16.2.3662-3677 